\title{
Tecnologias digitais de comunicação e ensino superior: contribuições da teoria da atividade em processos de ensino- -aprendizagem
}

\author{
Mariano Castro Neto
}

\begin{abstract}
Resumo
Apresentam-se neste artigo contribuições da Teoria da Atividade (TA) aos processos ensino-aprendizagem realizados com apoio de Tecnologias Digitais de Comunicação. A empiria se realizou no Componente Curricular: Educação Cultura e Mídia do curso Licenciatura em Pedagogia, na modalidade de ensino a distância, ofertado pelo Centro de Educação da UFPB. Trata-se de uma abordagem qualitativa, do tipo exploratória comparativa, cuja empiria se constituiu a partir de atividades realizadas via Ambiente Virtual de Aprendizagem: Moodle. Os sujeitos foram alunos e professores do referido curso, que, durante seis semestres dos anos de 2016, 2017 e 2018, responderam o questionário disponibilizado no AVA, com questões abertas e fechadas. Destes, foram selecionados os questionários com maior número de questões respondidas. Os dados mostram que processos ensino-aprendizagem, no contexto do Ensino Superior, com apoio de tecnologias digitais de comunicação, baseados nos fundamentos da TA, pressupõem uma transformação qualitativa do processo e não apenas uma transposição de métodos de aprendizagem, inicialmente concebidos para um ensino centrado no professor, didaticamente expositivo, e que reduz a dimensão avaliativa do processo ensino-aprendizagem à mera realização de exercícios e à aplicação de conhecimentos. Como continuidade deste estudo, procurar-se-á, à luz dos fundamentos teóricos da TA, reavaliar os instrumentos, as estratégias e categorias de análises utilizadas.
\end{abstract}

Palavras-chave:

teoria da atividade; processos ensino-aprendizagem; tecnologias digitais de comunicação. 


\title{
Digital technologies of communication and higher education: contributions from theory of activity in teaching learning processes
}

\begin{abstract}
The article presents contributions from Activity Theory (TA) to the teaching-learning processes carried out with the support of Digital Communication Technologies. The studied experience was developed in the scope of the Curricular Component: Education, Culture and Media, of the Degree in Pedagogy course, offered by the Education Center of UFPB, in the distance learning modality. It is a qualitative approach, of a comparative exploratory type, whose empiricism was constituted from activities carried out in a Virtual Learning Environment, such as Moodle. The study subjects are concentrated on the students and teachers of that course, who answered the questionnaire made available in the AVA, with open and closed questions, during six semesters of the years 2016, 2017 and 2018. The questionnaires with the largest number of answered questions were selected for analysis. The data reveal that teaching-learning processes, in the context of Higher Education, with the support of digital communication technologies, based on the fundamentals of AT, presuppose a qualitative transformation of the process and not just a transposition of learning methods, initially conceived for a teaching centered on the teacher, didactically expository, and which reduces the evaluative dimension of the teaching-learning process to the mere performance of exercises and the application of knowledge. As a continuation of this study, we will seek to reevaluate the instruments, strategies and categories of analysis used, in the light of the theoretical foundations of AT.
\end{abstract}

Keywords: activity theory. teaching-learning processes. digital communication technology.

\section{Technologies numeriques de la communication et de l'enseignement superieur: contributions de la theorie de l'activité dans les processus d'apprentissage de l'enseignement}

Résumé: L'article présente les contributions de la théorie de l'activité (TA) aux processus d'enseignement-apprentissage menés avec le soutien des technologies de la communication numérique. L'expérience étudiée a été développée dans le cadre de la composante curriculaire: éducation, culture et médias, du cours de licence en pédagogie, offert par le centre d'éducation de l'UFPB, dans la modalité d'apprentissage à distance. II s'agit d'une approche qualitative, de type exploratoire comparatif, dont l'empirisme a été constitué à partir d'activités menées dans un environnement d'apprentissage virtuel, tel que Moodle. Les sujets d'étude sont concentrés sur les étudiants et les enseignants de ce cours, qui ont répondu au questionnaire mis à disposition dans l'AVA, avec des questions ouvertes et fermées, pendant six semestres des années 2016, 2017 et 2018. Les questionnaires avec le plus grand nombre de réponses des questions ont été sélectionnées pour analyse. Les données révèlent que les processus d'enseignement-apprentissage, dans le cadre de l'enseignement supérieur, avec le soutien des technologies de communication numérique, basés sur les fondamentaux de l'AT, présupposent une transformation qualitative du processus et pas seulement une transposition de méthodes d'apprentissage, initialement conçues pour un enseignement centré sur l'enseignant, didactiquement explicatif, et qui réduit la dimension évaluative du processus d'enseignement-apprentissage à la simple réalisation d'exercices et à l'application des connaissances. Dans le prolongement de cette étude, nous chercherons à réévaluer les instruments, stratégies et catégories d'analyses utilisées, à la lumière des fondements théoriques de l'AT

Mots-clés: théorie de l'activité; processus d'enseignement-apprentissage; technologie de communication numérique.

\section{Tecnologías digitales de comunicación y educación superior: contribuciones desde la teoría de la actividad en los procesos de aprendizaje docente}

\begin{abstract}
Resumen: El artículo presenta aportaciones de la Teoría de la Actividad (AT) a los procesos de enseñanza-aprendizaje realizados con el apoyo de las Tecnologías de la Comunicación Digital. La experiencia estudiada se desarrolló en el ámbito del Componente Curricular: Educación, Cultura y Medios de Comunicación, del curso de Grado en Pedagogía, impartido por el Centro de Educación de la UFPB, en la modalidad de educación a distancia. Es un abordaje cualitativo, de tipo exploratorio comparativo, cuyo empirismo se constituyó a partir de actividades realizadas en un Entorno Virtual de Aprendizaje, como es Moodle. Los temas de estudio se concentran en los estudiantes y docentes de dicho curso, quienes respondieron el cuestionario puesto a disposición en la AVA, con preguntas abiertas y cerradas, durante seis semestres de los años 2016, 2017 y 2018. Los cuestionarios con mayor número de respuestas Se seleccionaron preguntas para su análisis. Los datos revelan que los procesos de enseñanza-aprendizaje, en el contexto de la Educación Superior, con el apoyo de las tecnologías de la comunicación digital, basados en los fundamentos de la TA, presuponen una transformación cualitativa del proceso y no solo una transposición de los métodos de aprendizaje, inicialmente concebidos para una enseñanza centrada en el docente, didácticamente expositiva, y que reduce la dimensión evaluativa del proceso de enseñanza-aprendizaje a la mera realización de ejercicios y aplicación de conocimientos. Como continuación de este estudio, buscaremos reevaluar los instrumentos, estrategias y categorías de análisis utilizados, a la luz de los fundamentos teóricos de la TA.
\end{abstract}

Palabras clave: teoría de la actividad; procesos de enseñanza-aprendizaje; tecnología de comunicación digital. 


\section{Introdução}

Historicamente, no Brasil, os cursos de Licenciatura, na sua grande maioria, constituíram-se perpetuando um modelo de dicotomia entre teoria e prática. De outro lado, considera-se que o ensino deve ser um processo de pesquisa, de investigação e produção de saberes que se transformem em mudanças efetivas e promovam a construção de um currículo flexível e integrado, apresenta-se como possibilidade de romper com essa dicotomia (Sacristán \& Pérez Gómez, 1998). Tais aspectos resultam particularmente relevantes, pois pressupõem um processo de planejamento integral do processo ensino-aprendizagem realizado em contexto do Ensino Superior com apoio de tecnologias digitais de comunicação, que defina o lugar e o papel do estudante, do professor, dos meios e ferramentas a serem utilizadas, a forma de delimitação do conteúdo de ensino e sua problematização e apresentação no contexto do plano integral de ensino-aprendizagem.

Sob a ótica pedagógica, a atividade de caráter experimental é fundamental para a construção do conhecimento e para a operacionalização dos componentes curriculares no âmbito acadêmico. Em uma perspectiva de gestão do conhecimento, aulas práticas são amplamente reconhecidas, no entanto, o enfoque dado a atividade experimental, em alguns casos, ainda são incipientes, entretanto vem se modificando na medida em que modelos epistemológicos, tendências pedagógicas inovadoras e as tecnologias digitais de comunicação são utilizadas em processos ensino-aprendizagem se popularizam.

Entende-se que essas concepções tornariam professores e alunos mais reflexivos sobre suas práticas, em um mundo no qual a informação e os conhecimentos circulam por meios tecnológicos cada vez mais sofisticados e poderosos. Acredita-se que os princípios teóricos da Teoria da Atividade se constituem em suporte teórico fundamental para identificar, a partir do conjunto de competências tecnológicas requeridas pelo mundo do trabalho, o caráter instrumental e teórico da TA aplicáveis em processos ensino-aprendizagem realizados no contexto do Ensino Superior por meio de tecnologias digitais de comunicação.

Com base em autores como: Castro Neto (2009), Damazio (2000), Gutiérrez (2002), Leontiev (1978), Vygotsky (1996), Lévy (1993), Tardif \& Lessard (2005), dentre outros, problematizou-se acerca da necessidade de investigar as implicações que as tecnologias digitais de comunicação oferecem para o desenvolvimento de competências tecnológicas no processo ensino-aprendizagem do componente curricular: Educação, cultura e Mídia, do $5^{\circ}$ período do curso de Licenciatura em Pedagogia, na modalidade a distância, da Universidade Federal da Paraíba - UFPB, à luz de princípios teóricos da Teoria da Atividade. 
Nesse sentido, optou-se em iniciar esta pesquisa a partir do seguinte questionamento: em que medida os princípios teóricos da Teoria da Atividade podem contribuir na organização didático-pedagógica da atividade de aprendizagem com apoio de tecnologias digitais de comunicação no contexto da educação superior? Nesta perspectiva, apresentam-se, neste artigo, alguns fundamentos da Teoria da Atividade que podem auxiliar o planejamento de atividades didático-pedagógicos com apoio de tecnologias digitais de comunicação.

\section{A Teoria Sócio-Histórica e seu contexto}

O principal ícone da Teoria Sócio-Histórica é L. S. Vygotsky (1896-1934) que, mesmo com sua morte precoce, deixou para a humanidade um importante legado. Após sua morte, os pesquisadores A. R. Luria (1902-1977), Alexey N. Leontiev (1904-1979), V. V. Davidov (1923-1985), Piotr Ya Galperin (1902-1988), D. B. Elkonin e N.F. Talízina rediscutiram e sistematizaram sua obra (Castro Neto, 2009).

As concepções filosóficas desenhadas por esse grupo de estudiosos foram fundamentadas nas ideias de Karl Marx (1979: 109) que a partir de sua teoria afirma que: "toda a vida social é essencialmente prática. Todos os mistérios que levam a teoria ao misticismo encontram a sua solução racional na práxis humana e no compreender desta práxis". Essa nova abordagem Vygotskiana surge no início do século XX, se contrapondo as duas grandes concepções psicológicas predominantes; a naturalista, que concebia a psicologia como uma ciência natural baseada na experimentação e a idealista, tida como a psicologia voltada à estrutura mental (Vygotsky, 1996).

Algumas fragilidades teórico-metodológicas da Psicologia nos primórdios do século XX foram apontadas, dentre as quais se destacam o fato de que tanto a psicologia naturalista como a idealista não eram baseadas em critérios objetivos. Não produziam análises e explicações por meio de métodos de fenômenos em elementos mais simples. Ao contrário, eram baseadas em descrições subjetivas e dirigidas a fenômenos globais, sem o devido rigor metodológico (Baquero, 1998). Assim, a psicologia experimental não abordava as funções psicológicas mais complexas do ser humano, nem a psicologia mentalista produzia descrições objetivas dos processos psicológicos tidos como complexos em termos aceitáveis, sobretudo para a ciência (Vygotsky, 1996).

Com o objetivo de superar essa crise, Vygotsky e seus colaboradores começaram a formular as bases da Teoria Sócio-Histórica, que deveria ser uma síntese ${ }^{1}$ das duas abordagens predominantes (Leontiev, 1978). Segundo Baquero (1998), a Teoria Sócio-Histórica fica explicitada em três ideias centrais: os Processos Psicológcos Superiores (PPS) têm uma origem histórica e social; as ferramentas e os signos são determinantes na constituição dos PPS; e abordagem dos PPS a partir de uma perspectiva genética. 


\section{A Origem dos Processos Psicológicos Superiores}

Os Processos Psicológicos Superiores² - PPS (percepção, linguagem, atenção, memória, voluntária, capacidade de generalização), se desenvolvem na relação da criança com os adultos ou parceiros mais experientes. Existem inicialmente no plano social, e depois no plano psicológico, ou seja, primeiramente se desenvolvem entre pessoas (nível interpsicológico) e depois no interior da pessoa (nível intrapsicológico). Trata-se de compreender o homem sócio-histórico, isto é, através do estudo da origem e do desenvolvimento do homem - filogênese e ontogênese - onde a atividade trabalho aparece como importante referência à suas formulações teóricas e uma das primeiras atividades que diferenciou o homem dos outros animais (Vygotsky, 1996).

A internalização dos PPS e de outras funções vão ao longo do processo de socialização do sujeito constituindo o seu psiquismo, as suas realidades interiores, que não são simplesmente cópias do plano externo, e sim resultados de uma apropriação das formas de ação-reflexão-ação que acontecem a partir das mediações semióticas, informações e interações dos conhecimentos internalizados por ele no seu contexto (Vygotsky, 1996).

Ao assumir que o sujeito constitui suas formas de ação, e que a sua consciência é formada a partir ou com base nas relações sociais, Vygotsky aponta caminhos para a superação da dicotomia social/individual. Deste modo, as interações são proposições que nos conduzem a conceber em bases novas a relação entre os planos social e individual da ação e a compreender o desenvolvimento psicológico como um curso de apropriação de formas culturais maduras de atividade social. Vygotsky (1988: 151) defende que "todo cultural é social. A cultura é produzida na vida e na atividade social do ser humano", onde os Processos Psicológicos Elementares - PPE são as bases para a formação dos Processos Psicológicos Superiores - PPS.

Além da linguagem que, segundo Luria (1990) e Vygotsky (1996), tem papéis determinantes na formação da atividade consciente do homem, o pensamento e a imaginação, do mesmo modo, como os outros PPS, foram desenvolvendo-se e complexificando-se ao longo da história social da humanidade.

\section{Desenvolvimento e Internalização de Conceitos Científicos}

O processo de interiorização ${ }^{3}$ de uma operação psicológica implica na reconstrução e na formação de PPS. A formação dessas estruturas, que Vygotsky chamou de PPS, ocorrem nas interações com a realidade objetiva, onde a relação sujeito/objeto é mediada por signos e símbolos e fundamentalmente pelo processo cultural e histórico da espécie. Sobre a interiorização e a formação de conceitos científicos o próprio 
Vygotsky acreditava que este processo traz consigo algumas características que sugerem transformações necessárias.

O processo de interiorização, nesse sentido, não é uma mera transferência de um plano para outro ou de uma dimensão para outra, mas da interiorização das operações que são produzidas no plano social, as quais são internalizadas inicialmente no nível interpsicológico e depois no intrapsicológico.

Pesquisadores apontam algumas categorias que julgam mais expressivas no âmbito da Teoria Sócio-Histórica. Baquero (1998), salienta a importância das operações com signos que resultam na linguagem, uma das categorias centrais da obra de Vygotsky em que o processo de internalização colabora na construção dos PPS. Ambos os processos se relacionam direta ou indiretamente com as funções psicológicas responsáveis pelo desenvolvimento cognitivo, bem como com o constructo da personalidade, e, especificamente, da atividade psicológica por onde flui o desenvolvimento do pensamento, da capacidade argumentativa, como o desenvolvimento dos afetos, sentimentos e vontades.

\section{Considerações Conceituais acerca da Atividade}

Como primeiro traço, Luria (1990: 71) entende que "[...] a atividade consciente do homem não está obrigatoriamente ligada a motivos biológicos". A grande maioria dos atos-atividades não depende de uma inclinação biológica, pois são regidos por mecanismos complexos; situa-se entre eles a necessidade cognitiva que impulsiona o sujeito na busca de outros conhecimentos. O homem possui a capacidade de refletir sobre seus atos presentes ou futuros. Este é o segundo aspecto que vai diferenciá-lo.

Assim, a capacidade de refletir na sua atividade consciente não deve ser um ato puro e simples exterior, e sim um conhecimento mais profundo das leis ou dos mecanismos que regem estas situações. O terceiro traço que difere a atividade consciente do homem do comportamento do animal é destacado em Luria (1990: 73): "a atividade consciente do homem possui ainda uma terceira fonte; a grande maioria dos conhecimentos e habilidades do homem se forma por meio da assimilação da experiência de toda a humanidade, acumulada no processo da história social”.

Ao discutir a importância da categoria trabalho e da formação da atividade consciente do homem, Luria (1990: 76) afirma que "[...] a preparação dos instrumentos (que às vezes subentendia também a divisão natural do trabalho) por si só já mudava radicalmente a atividade do homem primitivo, distinguindo-o do comportamento animal". No ato do homem esfregar uma pedra na outra, por exemplo, para produzir faíscas, o fogo carece, a priori, de um sentido4, mesmo que utilitário, e não de uma justificativa em termos biológicos. A ação adquire sentido somente a partir do uso do 
fogo produzido pelo movimento de esfregar duas pedras, o conhecimento do fogo e suas utilidades (Luria, 1990).

Gutiérrez (2002) acredita que o indivíduo encontra no seu convívio social as condições externas que organizam e influenciam o desenvolvimento de suas atividades, dos procedimentos, ações e mediadores semióticos utilizados. Para ele, a categoria atividade traz na sua essência o conceito do seu objeto, o qual aparece de duas formas: uma delas é na sua existência independente como sistema e a outra "é como imagem do objeto, como produto do reflexo de suas propriedades, o que se realiza como resultado da atividade" (Luria, 1990: 24).

\section{A Estrutura da Atividade}

O idealizador da Teoria da Atividade, Leontiev (1978: 67), afirma que a atividade pode ser comparada a uma unidade molecular e não a uma categoria ampla. Os elementos componentes de uma atividade consciente podem ser divididos em ações e procedimentos. Esta divisão ou decomposição das ações em procedimentos ocorre no plano das relações que são estabelecidas socialmente entre os sujeitos. A ação, portanto, é um átomo (Figura1) da atividade humana guiada por fins conscientes (Damazio, 2000).

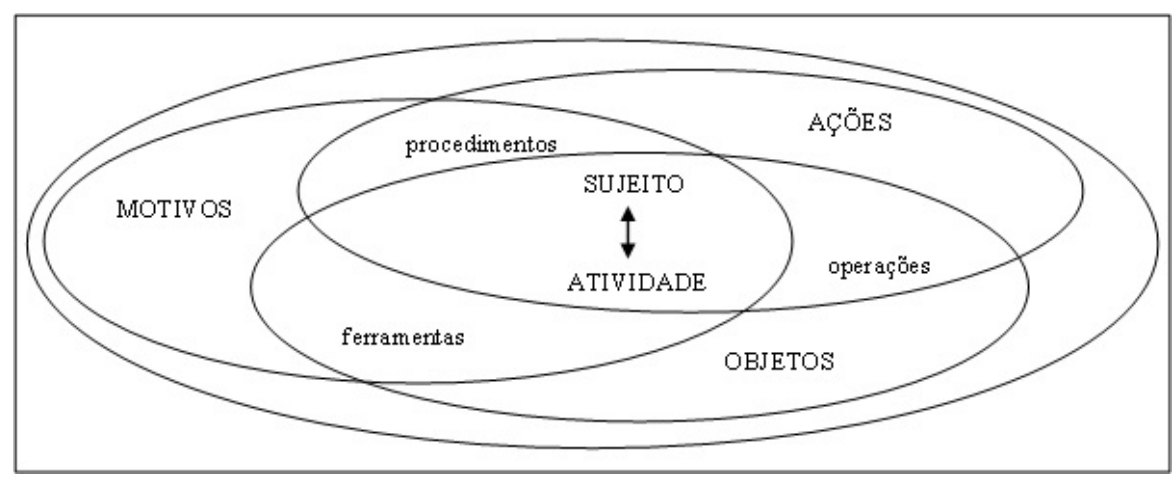

Figura 1. Elementos componentes de uma atividade Fonte: Castro Neto (2006: 47).

O objeto é um dos principais elementos reguladores das funções internas ou dos processos internos na estrutura da atividade. E outro regulador é a imagem como produto subjetivo da atividade. Produz-se uma dupla transição: "[...] a de objeto processo de atividade e a da atividade produto subjetivo. A transição do processo ao produto opera-se não só no pólo do sujeito; essa transição é mais notória ainda no pólo do objeto que se transforma pela atividade humana" (Gutiérrez, 2002: 24). 
No contexto da atividade de aprendizagem cada ação é formada por várias operações. Estas são o seu modo de operacionalização, ou seja, de execução, que estão relacionadas diretamente com as condições, com os meios e procedimentos necessários para o desenvolvimento da atividade e o alcance dos fins. A operação é indispensável para realização da ação, entretanto, não há identificação entre ambas. Dito de outro modo, a realização de uma ação pode ser realizada por diferentes operações. Por outro lado, uma operação também pode realizar diferentes ações (Gutiérrez, 2002).

Uma atividade sempre envolve artefatos, regras, procedimentos e formas próprias de organização. Esses materiais ou artefatos são criados e transformados a partir e durante o desenvolvimento da atividade, em que esta, para tomar forma, ou seja, chegar a seu «fim» absorve características do contexto em que ocorre (Leontiev, 1978).

Dentre as características de uma ação, destaca-se o fato de que ela é sempre orientada para um objetivo. Do ponto de vista operacional, uma ação está inserida em circunstâncias e em especificidades que interagem direta ou indiretamente durante sua execução. Assim, as operações são meios por onde a ação se realiza.

\section{As Dimensões Cognitivas da Atividade}

A estrutura da atividade tem como ponto de partida o sujeito e o objeto. Na abordagem cognitiva, segundo Gutiérrez (2002: 49), a "atividade do sujeito não se dirige ao ser aparente do objeto, e se o modifica de maneira ideal é só para depois reter mentalmente seu verdadeiro ser, penetrar na sua profundeza e compreender sua essência". Para este autor, os mecanismos e as características do processo cognitivo presentes numa atividade levam o sujeito a refletir sobre o objeto; e essa reflexão retorna ao sujeito no nível das funções superiores, e o leva a criar um novo objeto.

Essas características podem apresentar-se nas relações que são estabelecidas a partir de processos mediados entre o sujeito e o objeto, facilitando os processos cognitivos a partir de uma atividade. Tais reflexões possibilitam ulteriores transformações no objeto. Os processos cognitivos na atividade atingem um conhecimento mais elaborado, científico, que se desviou da cognição prática oriunda da divisão social do trabalho e se tornou conhecimento elaborado. A partir de processos cognitivos da atividade concreta e independente transformam-se em conhecimentos científicos (Gutiérrez, 2002).

Por outro lado, o conhecimento científico ou elaborado possui níveis empíricos e teóricos e, em geral, representa amplas situações de atividades cognitivas. Entretanto, possui relação com diversos objetos que exercem influências sobre os processos cognitivos da atividade. Quando estes processos se dirigem ao sujeito cognoscente, iniciam-se os processos de autoconhecimento, permanecendo no nível do conhecimento prático (Gutiérrez, 2002). 
Essas características, como afirmou Marx, são dialéticas, pois transformam o sujeito da atividade na medida em que são transformadas. E as ações-operações são instrumentalmente mediadas a partir de concepções transformadoras.

\section{O percurso metodológico deste estudo}

Os processos pedagógicos aqui analisados foram aplicados no Componente Curricular: Educação Cultura e Mídia, do curso de graduação em Licenciatura em Pedagogia, na modalidade de ensino a distância, ofertado pelo Centro de Educação da UFPB. Trata-se de uma abordagem qualitativa, do tipo exploratória comparativa, cuja empiria se constituiu a partir de atividades realizadas via Moodle. Os sujeitos deste estudo foram alunos e professores do respectivo curso, que, durante seis semestres dos anos: 2016, 2017 e 2018, responderam o questionário disponibilizado no AVA. Destes, identificaram-se questionários com maior número de questões respondidas.

Inicialmente, selecionamos as seguintes habilidades: Interpretação de textos; Elaboração de textos; Expressão escrita; Expressão oral, capacidade discursiva; Raciocínio indutivo e dedutivo; Aplicação de conhecimento em situações concretas; Domínio de terminologia básica; Crítica e autocrítica, capacidade de autoavaliação e Trabalho em equipe. A escala aplicada foi a proposta por Castro Neto (2009), em que também serviu de base na elaboração dos princípios teóricos da TA para a organização do trabalho docente realizados em ambientes virtuais de aprendizagem. A fase seguinte foi a tabulação de dados, organização das categorias de análise, classificação, tratamento e análise.

\section{Resultados e Discussões}

Com base na elaboração de um índice resumo das avaliações realizadas pelos professores com seus respectivos alunos, questionou-se como se autoavaliavam em relação às diversas habilidades implícitas no processo ensino-aprendizagem, com ênfase nas habilidades «interpretação de textos», «elaboração de textos» e «expressão escrita». Constatou-se que, aproximadamente $83,5 \%$ se autoavaliaram como portadores dos conceitos suficientes nas habilidades para «interpretação de textos», 80,8\% para "elaboração de textos», e 71,5\% para «expressão escrita» (Tabela 1). 
Tabela 1. Avaliação e autoavaliação dos estudantes pelos professores

\begin{tabular}{l|ll|c|c|c}
\hline \multicolumn{1}{c|}{ COLABORADORES } & \multicolumn{2}{l|}{ PROFESSORES } & \multicolumn{3}{|c}{ ESTUDANTES } \\
\hline \multicolumn{1}{c|}{ HABILIDADES } & $\mathbf{M} / \mathbf{S}$ & $\mathbf{I} / \mathbf{D}$ & $\mathbf{M} / \mathbf{S}$ & $\mathbf{S}$ & $\mathbf{I} \mathbf{D}$ \\
Interpretação de textos & 65,6 & 34,4 & & 83,5 & \\
Elaboração de textos & 55,5 & 44,5 & & 80,8 & \\
\hline Expressão escrita & 45,5 & 54,5 & & 71,5 & \\
\hline Expressão oral, capacidade discursiva & 65,6 & 34,4 & 20,8 & 75,7 & 3,5 \\
\hline Raciocínio indutivo e dedutivo & 54,5 & 45,5 & 80 & 80 & \\
Aplicação de conhecimento em situações & 52,8 & 47,2 & 80 & 80 & \\
concretas & & & & & \\
\hline Conhecimento de terminologia básica & 46,5 & 53,5 & 80 & 80 & \\
\hline Crítica e autocrítica, capacidade de autoavaliação & 57,5 & 42,5 & 80 & 80 & \\
\hline Trabalho em equipe & 58,6 & 41,4 & 80 & 80 & \\
\hline
\end{tabular}

$M / S$ = muito suficiente; $1 / D=$ insuficiente/deficiente; $S$ = suficiente.

Ao focar a análise em habilidades "expressão oral» e "capacidade discursiva», os dados mostram, como vê-se na Tabela 1, que 75,7\% consideraram-se «suficiente» em relação a essas habilidades. Estes dados são complementados com 3,5\% de estudantes que se autoavaliaram como «insuficiente» ou "deficiente», e 20,8\% como «muito suficiente». Referente à autoavaliação das habilidades para «raciocínio indutivo e dedutivo", "aplicação de conhecimentos em situações concretas", "domínio da terminologia básica», "crítica e autocrítica, capacidade de autoavaliação» e "trabalho em equipe", constatou-se que $80 \%$ ou mais, se autoavaliaram como portadores de desempenho "suficiente» ou «muito suficiente» para tais habilidades, conforme mostra a Tabela 1.

Por outro lado, quando o foco da análise se volta para habilidades como a capacidade de «aplicação de conhecimentos em situações concretas», se constatou que, aproximadamente $47,2 \%$ dos estudantes foram avaliados pelos professores com conceitos «insuficiente» ou «deficiente», conforme mostra a Tabela 1.

Os dados mostram que, $42,5 \%$ dos professores consideraram que os estudantes apresentaram insuficiente ou deficiente o "domínio da terminologia básica». Em contrapartida, 58,6\% foram considerados portadores de habilidades «suficientes» ou «muito suficientes» para o «trabalho em equipe». Para complementar os resultados, constataram-se que, $42,5 \%$ dos estudantes foram avaliados como «insuficiente» ou «deficiente» na «crítica e autocrítica», e na "autoavaliação» (Tabela 1).

Em se tratando da utilização das ferramentas apresentadas, onde a categoria de análise é a frequência de utilização das ferramentas, os dados apontaram que há variação na frequência de utilização das ferramentas de uma para outra, conforme mostra a Tabela 2. 
Tabela 2. Frequência de uso das ferramentas do Moodle pelos professores

\begin{tabular}{l|c|c|c|c}
\hline \multicolumn{1}{c|}{ FERRAMENTAS } & F \% & O \% & R \% & N \% \\
\hline Agenda & 49,5 & 31,2 & 19,3 & \\
Chat & 52,3 & 47,7 & & \\
\hline Material de apoio & 41.5 & 58.5 & & \\
\hline E-mail isolado & 64,5 & & 35,5 & \\
Fórum específico & 66,5 & 23,3 & & 10,2 \\
\hline Mala direta & 90,9 & 9,1 & & \\
\hline Objeto de aprendizagem & 94,9 & 5,1 & & \\
\hline Fórum geral & 35,5 & 29,5 & 21,5 & 13,5 \\
\hline Trabalho colaborativo & 65,5 & 34,5 & & \\
\hline
\end{tabular}

$\mathrm{F}=$ frequentemente $\mathrm{O}=$ ocasionalmente; $\mathrm{R}=$ raramente $\mathrm{e} \mathrm{N}=$ nunca.

Em relação às sugestões que poderiam ser utilizadas no aperfeiçoamento do processo de ensino-aprendizagem e na utilização das diferentes ferramentas disponibilizadas no Moodle, os dados mostram que os sujeitos informantes usuários não tiveram dificuldades na navegabilidade, bem como na utilização das ferramentas. A ferramenta «objeto de aprendizagem» foi considerada pelos colaboradores como a mais eficaz das ferramentas disponíveis no ambiente de apoio a aprendizagem, «mala direta» a segunda e o «fórum específico» a terceira, seguida pelas demais ferramentas (Tabela 2).

Para os colaboradores deste estudo, o conhecimento técnico das ferramentas utilizadas em processos ensino-aprendizagem mediados por tecnologias digitais é apontado como um dos aspectos mais importantes na formação do professor. Além da necessidade do conhecimento técnico do ambiente pelo professor, é fundamental, segundo os colaboradores deste estudo, que os docentes tenham clareza dos fundamentos teóricos de suas práticas pedagógicas realizadas em contextos de utilização de tecnologias digitais de comunicação. Esses fundamentos teóricos podem possibilitar uma organização do trabalho docente virtual, elaboração de critérios de avaliação do processo ensino-aprendizagem, além de explorar as potencialidades pedagógicas das ferramentas, transformando-as em meios para a construção do conhecimento.

$\mathrm{Na}$ atividade de usuário é o colaborador quem identifica qual o melhor padrão de usabilidade e navegabilidade. E quem também identifica os principais problemas. Dentre os problemas apontados pelos colaboradores deste estudo destacam-se os de interface, de integração de módulos, de conexão e limitações de utilização de recursos hipermídia, terminologia para integração das ferramentas, de gestão do ambiente, administrativo e acadêmico.

Em relação à preferência por uma ou por outra ferramenta do ambiente, constatou-se variação. As ferramentas mais referidas como preferidas e com maior frequência de utilização foram: Objeto de aprendizagem, fórum e material de apoio, ou seja, 94,9\% 
dos colaboradores, conforme mostra a Tabela 2, elegeram o chat como a ferramenta preferida. Este índice é resultado das análises das questões fechadas.

Tabela 3 - Preferência de utilização das ferramentas do Moodle

\begin{tabular}{cc}
\hline FERRAMENTAS & PREFERENCIA \\
\hline Objeto de aprendizagem & $94,9 \%$ \\
Mala direta & $90,9 \%$ \\
\hline Fórum específico & $66,5 \%$ \\
\hline
\end{tabular}

Sob esse aspecto, pesquisadores como Palloff \& Pratt (2002), sugerem que os materiais instrucionais disponibilizados e utilizados devem ser acessíveis, de fácil consulta, devendo conduzir progressivamente o aprendiz ao conhecimento, à compreensão, à análise e à aplicação dos conteúdos apresentados. Processos ensino-aprendizagem realizados por meio de tecnologias digitais de comunicação assumem caráter flexíveis ao grande contingente de indivíduos, independentemente de distância física, além de tornar a difusão de informações uma prática constante, antes centralizada em poucos locais.

A partir desse cenário, é possível afirmar que, processos ensino-aprendizagem, no contexto do Ensino Superior, realizados com apoio de tecnologias digitais de comunicação, parece assumir um caráter cada vez mais dinâmico, colaborativo e, sobretudo, complexo. O que nos remete a (re)pensar conceitos e categorias acerca da aprendizagem, avaliação, mediação etc.

Sob a ótica pedagógica, o professor que se dedica à prática docente com o apoio de tecnologias digitais de comunicação deve ter conhecimentos específicos da área, mas, sobretudo, deve ser capaz de utilizar procedimentos metodológicos apropriados, conferindo significado aos currículos e às práticas de ensino, de acordo com os objetivos didático-pedagógicos a atingir. Além disso, na perspectiva metodológica, entende-se que é importante discutir e elaborar princípios teóricos que orientem a organização da atividade de aprendizagem, nesses espaços, a partir de um referencial teórico.

\section{Conclusões}

Este estudo permitiu realizar algumas considerações relevantes para problematizar as implicações que as tecnologias digitais de comunicação oferecem para o desenvolvimento de novas modalidades do processo ensino-aprendizagem, aplicando as contribuições que a Teoria da Atividade pode potencializar para uma utilização efetiva dessas tecnologias para apoiar a aprendizagem.

Dentre as categorias da TA, destacam-se «motivo» e "orientação a fins", que, neste caso, sublinham a consciência dos sujeitos usuários de tecnologias digitais de 
comunicação sobre a clara importância da utilização dessas tecnologias. Pressupõe ainda uma mudança de atitude por parte do estudante e do professor no que se refere ao papel e ao desempenho da atividade no processo ensino-aprendizagem. Com a utilização de tecnologias digitais de comunicação no contexto da educação superior, entende-se que o estudante aprende por meio de sua própria atividade, sendo esta realizada por um sujeito motivado, com consciência dos fins que espera obter. Em relação ao papel do professor, este experimenta mudanças relevantes; passa de um transmissor verbal de conteúdos de ensino para um mediador ativo do processo, criador de situações de aprendizagem elaboradas para garantir que sua realização possibilite o alcance dos resultados esperados.

Esses aspectos evidenciam a importância de planejamento integral do processo ensino-aprendizagem que defina o lugar e o papel do aluno, do professor, dos meios e ferramentas a serem utilizadas, a forma de delimitação do conteúdo de ensino e sua problematização e apresentação no contexto do plano integral de ensino-aprendizagem. Mas, se os conteúdos continuam sendo apresentados discursivamente, mediante uma simples transcrição de textos para o computador, e o professor se coloca no processo como um transmissor de conteúdos, pode-se dizer sob o ponto de vista pedagógico, que o aluno fica reduzido ao papel de receptor de conteúdos, ou seja, se está diante de uma modalidade de ensino-aprendizagem que utiliza tecnologia do século XXI para realizar processos ensino-aprendizagem «medieval».

Outra contribuição da Teoria da Atividade, que oferece elementos norteadores para a abordagem do processos ensino-aprendizagem realizados em contextos de utilização de tecnologias digitais de comunicação, é a unidade do inter-psicológico e intra-psicológico no desenvolvimento dos Processos Psicológicos Superiores implícitos no dito processo. Esse princípio teórico pressupõe a necessidade de inter-relações dinâmicas entre os integrantes de redes sociais digitais, e destes com os professores, mediante um processo de intercâmbio comunicativo externo que induza à interiorização da aprendizagem e à consolidação de abstrações e generalizações realizadas em nível de atividade mental interna.

Para Vygotsky (1996) e Leontiev (1978), a apropriação de conhecimento conceitual neste nível pressupõe necessariamente uma atividade sensorial-concreta, externa, que, enriquecida com as interações dialógicas com colegas e professores, é sistematizada na linguagem e interiorizada.

Como síntese final, pode-se afirmar que processos ensino-aprendizagem realizados no contexto do Ensino Superior, mediados por tecnologias digitais de comunicação, tendo como base os fundamentos da Teoria da Atividade, pressupõem uma transformação qualitativa do processo e não simplesmente uma transposição de métodos de aprendizagem, inicialmente concebidos para um ensino centrado no professor, didaticamente expositivo e que reduz a dimensão avaliativa do processo 
ensino-aprendizagem à mera realização de exercícios e à aplicação de conhecimentos. Como continuidade deste estudo, procurar-se-á à luz dos fundamentos teóricos da TA, reavaliar os instrumentos, as estratégias e categorias de análises utilizadas.

\section{Notas}

${ }^{1}$ Para Vygotsky, a síntese de dois elementos não é meramente a soma ou justaposição destes, mas a emergência de algo novo. Este novo elemento não existia nos anteriores e sua existência se deu a partir da interação desses num processo de transformação que gera novos elementos. Neste sentido, a síntese para Vygotsky tem um significado importante, ou seja, a busca de uma síntese para a psicologia integra, numa mesma perspectiva, o homem como ser social, como membro da espécie humana e participante de um processo histórico (Leontiev, 1978).

2 [...] Os processos psicológicos superiores são especificamente humanos, enquanto histórico e socialmente constituídos. É produto da linha de desenvolvimento cultural, sua constituição, e, em certo sentido, contingente. Pressupõem a existência dos processos elementares, mas estes não são condições suficientes para sua aparição. Quer dizer, os PPS não são os desideratos ou estado avançado dos processos elementares, que por sua evolução intrínseca se convertem em superiores. Şão, na verdade, muito mais complexos, porque o desenvolvimento parece incluir mudanças na estrutura e função dos processos que se transformam (Baquero, 1998: 27).

${ }^{3}$ [...] Contrapondo-se à interpretação simplista atribuída ao respectivo conceito, o qual o interpretava como uma espécie de transferência ou cópia de conteúdos externos no centro de uma teoria. Ao contrário, afirma Baquero (1998: 34), “... os processos de interiorização seriam os criadores de tal espaço interno. Quer dizer, deve-se conceitualizar a internalização como criadora de consciência e não como a recepção na consciência de conteúdos externos".

${ }^{4}$ [...] O sentido se exprime nas significações, e não o contrário. O sentido é uma relação que surge na atividade cotidiana, traduzindo a relação do motivo ao fim. Todo sentido é sentido de algo, isto é, de manifestações humanas. Desta forma, não há sentido em si mesmo puro. O sentido particular depende do motivo impulsionador da atividade realizada numa determinada ação. Enfim, o sentido pessoal depende do motivo. O surgimento do motivo cria a disposição para a ação (Damazio, 2000: 51).

5 [...] As significações existem nas relações dos sujeitos humanos concretos. Elas são elaboradas historicamente e o homem se apropria delas como se apropria de um instrumento. A significação representa a forma pela qual um homem absorve as experiências produzidas historicamente pela humanidade. Ela pertence, pois, ao mundo dos fenômenos objetivos históricos. Leontiev (1978: 94) define a significação como sendo "aquilo que num objeto ou fenômeno se descobre num sistema de ligações, de interações e de relações. É refletida e fixada na linguagem, o que lhe confere a sua estabilidade" (Leontiev, 1978: 52).

\section{Referências Bibliográficas}

\section{Baquero, R. (1998). Vygotsky e a aprendizagem escolar. Porto Alegre: Artes Médicas.}

Castro Neto, M. (2006). Da teoria da atividade a atividade docente em ambientes virtuais de apoio à aprendizagem. Tese de Doutorado. Florianópolis: Universidade Federal de Santa Catarina.

Castro Neto, M. (2009). Educação a distância sem distância. Florianópolis: Pandion.

Damazio, A. (2000). O desenvolvimento de conceitos matemáticos no contexto do processo extrativo de carvão. Tese de Doutorado. Florianópolis: Universidade Federal de Santa Catarina.

Gutiérrez, A. J. C. (2002). O problema científico: construção formal ou delimitação no real. Tese de Doutorado. Florianópolis: Universidade Federal de Santa Catarina.

Leontiev, A. N. (1978). Actividad, conciencia y personalidad. Buenos Aires: Ediciones ciências Del hombre. 
Lévy, P. (1993). As tecnologias da inteligência - o futuro do pensamento na era da informática. Rio de Janeiro: Editora 34.

Luria, A. R. (1990). Desenvolvimento cognitivo: seus fundamentos culturais e sociais. São Paulo: Ícone.

Marx, K. \& Engels, F. (1979). Ideologia alemã. São Paulo: Ciências Humanas.

Palloff, M. \& Pratt, K. (2002). Construindo comunidades de aprendizagem no ciberespaço. Porto Alegre: Artmed.

Sacristán, J. G. \& Pérez Gómez, A. I. (1998). Compreender e transformar o ensino. 4. ed. Porto Alegre: Artmed.

Tardif, M. \& Lessard, C. (2005). O trabalho docente: elementos para uma teoria da docência como profissão de interações humanas. Petrópolis, RJ: Vozes.

Vygotsky, L. S. (1996). Teoria e método em psicologia. São Paulo: Martins Fontes.

Mariano Castro Neto Possui Graduação em Pedagogia pela Universidade Tuiuti do Paraná (1996), Mestrado em Ergonomia pela Universidade Federal de Santa Catarina (2000) e Doutorado em Mídia e Conhecimento pela Universidade Federal de Santa Catarina (2006).

E-mail: mariano@ce.ufpb.br Orcid: 0000-0002-5926-0486

Correspondência: Mariano Castro Neto Universidade Federal da Paraíba - Campus I Centro de Educação (CE) Programa de Pós-Graduação em Políticas Públicas, Gestão e Avaliação da Educação Superior (MPPGAV) Cidade Universitária - CEP 58051-900 - João Pessoa-PB-Brasil

Data de submissão: Setembro de 2019

Data de avaliação: Dezembro de 2019

Data de publicação: Novembro 2020 